\title{
Impact of Chymosin- and Plasmin-Mediated Primary Proteolysis on the Growth and Biochemical Activities of Lactobacilli in Miniature Cheddar-Type Cheeses
}

\author{
M. M. Milesi, ${ }^{*}$ P. L. H. McSweeney, $†$ and E. R. Hynes* ${ }^{* 1}$ \\ *Instituto de Lactología Industrial, Facultad de Ingeniería Química, Universidad Nacional del Litoral-CONICET (Consejo Nacional de \\ Investigaciones Científicas y Técnicas), $1^{\circ}$ de Mayo, 3250-(3000) Santa Fe, Argentina \\ †Department of Food and Nutritional Sciences, University College, Cork, Ireland
}

\begin{abstract}
Strongly proteolytic starters seem to improve the growth of nonstarter lactobacilli during cheese ripening, but no information is available on the impact of the nonmicrobial proteases usually active in cheese on their development. In the current study, the influence of chymosin- and plasmin-mediated proteolysis on the growth and biochemical activities of lactobacilli during ripening of miniature Cheddar-type cheeses, manufactured under controlled microbiological conditions, was studied. Two experiments were performed; in the first, residual chymosin activity was inhibited by the addition of pepstatin, and in the second, plasmin activity was increased by adding more enzyme, obtained in vitro through the activation of plasminogen induced by urokinase. Cheeses with or without a Lactobacillus plantarum I91 adjunct culture and with or without added pepstatin or plasmin solution were manufactured and ripened for $60 \mathrm{~d}$. The addition of the adjunct culture resulted in enhancement of secondary proteolysis, evidenced by an increase in the total content of free amino acids (FAA) and modifications of the individual FAA profiles. Reduction in residual chymosin activity caused a decrease in primary and secondary proteolysis, characterized by the absence of $\alpha_{\mathrm{s} 1}$-casein hydrolysis and reduced production of peptides and FAA, respectively. The increase in plasmin activity accelerated primary proteolysis but no enhancement of secondary proteolysis was observed. Chymosin- and plasmin-mediated proteolysis did not influence the growth and biochemical activities of adventitious or adjunct lactobacilli, indicating that it is not a limiting factor for the development and proteolytic-peptidolytic activities of lactobacilli in the cheese model studied.
\end{abstract}

Key words: nonstarter lactobacilli, plasmin, chymosin, proteolysis

Received March 22, 2008

Accepted May 6, 2008

${ }^{1}$ Corresponding author: ehynes@fiq.unl.edu.ar

\section{INTRODUCTION}

Nonstarter lactic acid bacteria (NSLAB) are adventitious microorganisms that contaminate nearly all cheeses; they are mostly lactobacilli, but enterococci, pediococci, and Leuconostoc spp. can also be present in cheese as NSLAB (Hynes et al., 2001; Quiberoni et al., 2004). The NSLAB in cheese probably originate from raw milk (Turner et al., 1986; Jordan and Cogan, 1999; Christiansen et al., 2006); alternatively, they may recontaminate milk after pasteurization (Somers et al., 2001).

Cheese is a rather hostile environment for microbial growth: it has low $\mathrm{pH}(\sim 5)$ and high salt-in-moisture content (4 to $6 \%$ ), lacks a fermentable carbohydrate, is anaerobic, and may contain bacteriocins produced by starter bacteria (Fox et al., 2000). The NSLAB typically grow from low numbers $\left(10^{1}\right.$ to $\left.10^{4} \mathrm{cfu} / \mathrm{g}\right)$ in fresh curd to $10^{7}$ to $10^{8} \mathrm{cfu} / \mathrm{g}$ after 3 or $4 \mathrm{mo}$ of ripening, and therefore become the dominant viable microflora in the mature cheese (Peterson and Marshall, 1990; McSweeney et al., 1993).

The effect of several technological variables of the cheesemaking process and cheese ripening on NSLAB growth has been studied. Lane et al. (1997b) reported that moisture and salt-in-moisture contents have little effect on the development of NSLAB, provided that the values are within the typical ranges found in Cheddar cheese. Ripening temperature, on the contrary, has a significant influence on the rate and extent of NSLAB development: lower numbers of NSLAB were found when ripening temperature decreased (Martley and Crow, 1993; Shakeel-Ur-Rehman et al., 2000). On the other hand, rapid cooling of the curd after pressing has been pointed out as a determinant for a slow development of NSLAB (Fox et al., 1993; Folkertsma et al., 1996).

A main issue regarding NSLAB growing in cheese that remains unclear is their energy source. A few studies on this subject have been performed in vitro; free amino acids (FAA), peptides, lactose, citrate, pyru- 
vate, glycerol, products of starter cell lysis, and carbohydrates released from $\mathrm{k}$-casein or from glycoproteins in the milk-fat globule membrane have been proposed as potential energy sources (Thomas, 1987; Peterson and Marshall, 1990; Martley and Crow, 1993; Williams et al., 2000; Adamberg et al., 2005).

The influence of primary starter on NSLAB growth has also been studied, and it is linked to the availability of substrates and growing factors for NSLAB flora in the cheese. Thomas (1987) discovered that NSLAB were able to grow on washed cell suspensions of lactococci and suggested that highly autolytic starters may increase the growth of NSLAB in cheese by supplying carbon and energy sources such as ribose. However, further studies did not confirm this hypothesis: highly proteolytic starter strains, rather than autolytic starter strains, stimulate the growth of lactobacilli during cheese ripening (Wilkinson et al., 1994; Lane et al., 1997b; Hynes et al., 2001). The fact that proteolytic activity of the starter is implied in NSLAB growth was also suggested by the study of Di Cagno et al. (2003), which reported that the hydrolytic activity of cell wall proteases from lactic starter favorably affected the growth rate and final number of lactobacilli in vitro and in a cheese slurry system.

On the other hand, cell wall proteases from lactic starter are not the only proteases present in cheese. Indigenous milk proteases, notably plasmin, and usually added proteases such as rennet are active in cheese and hydrolyze casein into several fragments during ripening. In low-cooked cheeses such as Cheddar, primary proteolysis is mainly mediated by the action of chymosin rather than plasmin. The main substrate of chymosin is $\alpha_{\mathrm{s} 1}$-casein, which is degraded with the production of $\mathrm{a}_{\mathrm{s} 1}-\mathrm{CN}$ (f1-23) and $\mathrm{a}_{\mathrm{s} 1}-\mathrm{CN}$ (f24-199). The former peptide is rapidly hydrolyzed by starter proteinases to smaller peptides, which undergo further breakdown to amino acids by the action of peptidases of starter and NSLAB. Preferential substrates for plasmin in cheese are $\alpha_{\mathrm{s}^{-}}$and B-caseins; the breakdown of the latter gives the $\mathrm{Y}^{- \text {caseins }}\left(\mathrm{Y}_{1}, \mathrm{Y}_{2}\right.$, and $\mathrm{Y}_{3}$; Fox and Stepaniak, 1993; Fox et al., 2000). The influence of these biochemical transformations due to nonmicrobial proteases usually active in cheese on NSLAB growth has not been studied to date.

The objective of this work was to assess the influence of primary proteolysis due to residual coagulant and plasmin activities on the growth and biochemical activity of lactobacilli in miniature Cheddar-type model cheeses manufactured under controlled microbiological conditions. For that purpose, the impact of primary proteolysis on both the indigenous NSLAB population and an adjunct culture of Lactobacillus plantarum I91, were studied.

\section{MATERIALS AND METHODS}

\section{Milk Samples}

The raw whole milk used for manufacture was obtained from a local farmer. Milk samples were analyzed for composition using a Milkoscan FT 120 equipment (Foss Electric, Hillerød, Denmark) and standardized to a casein to fat ratio of 0.7 . Raw milk for cheese manufacture was batch-pasteurized at $65^{\circ} \mathrm{C}$ for $30 \mathrm{~min}$ (pilot plant, University College, Cork, Ireland). Counts of adventitious lactobacilli on Rogosa agar (Merck, Darmstadt, Germany) by incubation at $30^{\circ} \mathrm{C}$ for $5 \mathrm{~d}$ were performed on raw and pasteurized milk to evaluate the microbiological quality of the raw milk and the effectiveness of the heat treatment.

\section{Experimental Design and Cheese Manufacture}

Two independent cheesemaking experiments were performed to study the effect of residual chymosin and plasmin activities on the growth and biochemical activity of lactobacilli during cheese ripening. In both cases 2 factors were studied, each at 2 levels: presence or absence of an adjunct culture of $L b$. plantarum I91 and modified nonmicrobial protease levels. The adjunct culture was selected from the NSLAB collection of the Instituto de Lactología Industrial (INLAIN, Santa Fe, Argentina), based on its technological properties, resistance to biological barriers, and probiotic potential (Bude-Ugarte et al., 2006). The influence of residual chymosin and plasmin activities was studied by means of reducing and increasing the enzymatic activities, respectively, by adding pepstatin (a potent competitive inhibitor of aspartyl proteinases) and plasmin solution.

For each experiment, 2 cheesemaking trials (trials 1 and 2) of miniature Cheddar-type cheeses were performed. Miniature Cheddar-type cheeses were manufactured from $200 \mathrm{~mL}$ of pasteurized milk following the procedure of Shakeel-Ur-Rehman et al. (1998a) adapted to aseptic conditions (Milesi et al., 2008). Starter culture was added at $0.5 \%$ (vol/ $/ \mathrm{vol})$ into cheesemilk at $31^{\circ} \mathrm{C}$; it consisted of a strain of Lactococcus lactis ssp. lactis commonly used in Cheddar cheese manufacture (Shakeel-Ur-Rehman et al., 1998a). After enrichment with $1 \mathrm{M} \mathrm{CaCl}_{2}(660 \mu \mathrm{L} / \mathrm{L})$, milk was clotted with rennet $(217.5 \mu \mathrm{L} / \mathrm{L}$ Maxiren 180, DSM Food Specialties, Delft, the Netherlands). Coagulum was cut when optimal firmness was developed using sterile stainless steel tools. After curd healing, the mixture of curds and whey was stirred slowly, and then cooked at $38^{\circ} \mathrm{C}$ while stirring more rapidly with a magnetic stirrer until the $\mathrm{pH}$ reached 6.2. Whey and curds were then transferred 
to sterile plastic centrifuge bottles and centrifuged at room temperature for $60 \mathrm{~min}$ at 1,700 $\times \mathrm{g}$ (MSE Major centrifuge, MSE Scientific Instruments, Crawley, UK). After whey drainage, cheeses were placed in a water bath at $36^{\circ} \mathrm{C}$ until $\mathrm{pH}$ reached 5.2 to 5.3 and then recentrifuged at $1,700 \times g$ for $20 \mathrm{~min}$. Cheeses were salted by immersion in sterile brine at room temperature for 30 min, after which they were removed, dried with sterile tissue paper, and vacuum packed.

Glass beakers, centrifuge bottles, miniature tools, brine, and $\mathrm{CaCl}_{2}$ solution were sterilized by autoclaving $\left(121^{\circ} \mathrm{C}\right.$ for $\left.15 \mathrm{~min}\right)$. Rennet was sterilized by filtration through $0.45-\mu \mathrm{m}$ membranes, and tissue paper was sterilized in an oven at $120^{\circ} \mathrm{C}$ for $4 \mathrm{~h}$.

For experiments in which rennet activity was modified, on each day of manufacture, 4 miniature Cheddartype cheeses were made: a control cheese $(\mathbf{C})$, a control cheese to which pepstatin solution was added (CP), an experimental cheese with the addition of $L b$. plantarum I91 as adjunct culture (E), and an experimental cheese prepared as for $\mathrm{E}$ but with the addition of pepstatin solution (EP). Pepstatin A (Sigma, Poole Dorset, UK) was added $(15 \mu \mathrm{mol} / \mathrm{L})$ to the curd-whey mixture at the start of cooking as described by Shakeel-Ur-Rehman et al. (1998b). When used, Lb. plantarum I91 was cultivated twice in de Man, Rogosa, and Sharpe (MRS) broth at $34^{\circ} \mathrm{C}$ overnight. An aliquot of this broth, sufficient to provide a concentration of $10^{6} \mathrm{cfu} / \mathrm{mL}$ in the cheesemilk, was centrifuged for $20 \mathrm{~min}$ at $8,000 \times \mathrm{g}$ and $4^{\circ} \mathrm{C}$. The pellet was washed twice with $0.1 \mathrm{M}$ sodium phosphate buffer ( $\mathrm{pH}$ 7), resuspended in the same buffer, and added into the experimental vats.

For experiments in which plasmin activity was increased, 4 miniature Cheddar-type cheeses were made on each day of manufacture: a control cheese (CC), a control cheese with the addition of plasmin solution (CPL), an experimental cheese containing $L b$. plantarum I91 as adjunct culture (EE), and an experimental cheese with plasmin solution plus adjunct culture (EPL). Plasmin solution was obtained in vitro through the activation of its inactive precursor plasminogen, induced by urokinase, as described by Richardson and Pearce (1981) with some modifications. An aliquot of $12.5 \mathrm{~mL}$ of plasminogen solution $(8.7 \mathrm{mg} / \mathrm{mL}$ solution; Sigma, Poole, UK) was mixed with $12.5 \mathrm{~mL}$ of urokinase solution (1,000 Ploug units/mL; Sigma) and the volume made up to $250 \mathrm{~mL}$ by the addition of $0.05 \mathrm{M}$ Tris- $\mathrm{HCl}$ buffer, $\mathrm{pH}$ 8.5, containing $0.02 M$ lysine, $0.14 \mathrm{M} \mathrm{NaCl}$, and $50 \%(\mathrm{vol} / \mathrm{vol})$ glycerol. The mixture was incubated for $90 \mathrm{~min}$ at $37^{\circ} \mathrm{C}$ in a water bath. Plasmin activity was assessed in the solution at the beginning of the incubation stage (time 0) and every $15 \mathrm{~min}$, by the method of Richardson and Pearce (1981), to determine the optimal conditions for the conversion of plasminogen to plasmin. Plasmin activity in the mixture increased gradually with time and was greatest after incubation for $60 \mathrm{~min}$. The resultant solution was heated at $70^{\circ} \mathrm{C}$ for $10 \mathrm{~min}$ before use to destroy any microflora possibly present. Plasmin solution was added into the milk of vats CPL and EPL at a proportion of approximately $2.5 \%$ (vol/vol); higher levels were avoided in order not to excessively dilute cheesemilk. The solution was added 30 min before the starter culture to ensure maximum binding of plasmin to the casein micelles (Farkye and Fox, 1992). Lactobacillus plantarum I91 was cultivated in MRS broth as described above. Because the plasmin experiments were performed after rennet experiments, the inoculation dose of lactobacilli in cheesemilk was diminished to $10^{-4} \mathrm{cfu} / \mathrm{mL}$ after considering the results of the first trial. For the same reason, maturation took place at $12^{\circ} \mathrm{C}$ for $60 \mathrm{~d}$ in plasmin experiments, whereas in the rennet experiment cheeses were ripened at $8^{\circ} \mathrm{C}$ for $60 \mathrm{~d}$.

A total of 48 miniature cheeses were manufactured for each experiment ( 24 cheeses per trial, 6 replicates obtained in different cheesemaking days for each cheese type). In both experiments, 2 control and 2 experimental cheeses were taken for analysis after 1,15 , 30,45 , and $60 \mathrm{~d}$ of ripening; the sixth cheese replicate of each type was used as a backup. After sampling for microbiological counts, the cheeses were grated immediately and stored at $-20^{\circ} \mathrm{C}$ until analysis.

\section{Analyses of Cheeses}

Gross Composition and Microbiological Counts. Gross composition analyses were performed in triplicate on 30-d-old cheeses. Moisture (oven drying at 102 $\pm 1^{\circ} \mathrm{C}$ ) and protein content (macro-Kjeldahl) were analyzed according to the International Dairy Federation (IDF, 1982) and IDF (1993), respectively. Salt content was determined by the method of Fox (1963). The $\mathrm{pH}$ was measured during cheesemaking and in the final products by placing the electrode of the $\mathrm{pH}$ meter (model $720 \mathrm{pH}$ meter, Orion Research Inc., Boston, MA) in contact with the curd or grated cheese, respectively.

Microbiological counts were performed in duplicate after 1, 15, 30, 45, and $60 \mathrm{~d}$ of ripening. Cheese samples $(10 \mathrm{~g})$ were homogenized for $5 \mathrm{~min}$ with $90 \mathrm{~mL}$ of a sterile $2 \%(\mathrm{wt} / \mathrm{vol})$ trisodium citrate solution in a Lab Blender 400 Stomacher (Seward Ltd., London, UK) and serially diluted 10 -fold using Ringer solution. Starter bacteria were enumerated on M17 agar (Merck) after incubation at $30^{\circ} \mathrm{C}$ for $3 \mathrm{~d}$. The adjunct culture and NSLAB in experimental and control cheeses, respectively, were determined on Rogosa agar (Merck) after incubation at $30^{\circ} \mathrm{C}$ for $5 \mathrm{~d}$. 
Measurement of Residual Coagulant Activity. Residual coagulant activity in the cheeses was analyzed in triplicate after $30 \mathrm{~d}$ of ripening using a slight modification of the method of Hurley et al. (1999), as described by O'Mahony et al. (2005). Residual coagulant activity was expressed as enzyme activity units per hour and grams of dry matter, where 1 unit of enzyme activity is defined as the activity necessary to release $1 \mathrm{nmol}$ of the product peptide ([ $\mathrm{NO}_{2}$-Phe]-ArgLeu) from the heptapeptide substrate per hour at $37^{\circ} \mathrm{C}$ and $\mathrm{pH} 3.2$.

Measurement of Plasmin Activity. Thirty-day-old cheeses were assayed in triplicate for plasmin activity by a modification of the method of Richardson and Pearce (1981), as described by Upadhyay et al. (2004). Plasmin activity in the cheeses was expressed as plasmin units per grams of cheese, where 1 unit was defined as the activity necessary to release $1 \mathrm{nmol}$ of 7-amino-4-methyl coumarin (AMC) from Suc-ala-PheLys-AMC per minute at $\mathrm{pH} 7.5$ and $25^{\circ} \mathrm{C}$.

Assessment of Proteolysis. Proteolysis was assessed on 1-, 30-, and 60-d-old cheeses. Casein degradation was assessed by urea-PAGE, whereas peptide profiles and levels of individual FAA were determined by reverse phase-HPLC (RP-HPLC), all as described by Milesi et al. (2008).

\section{Statistical Analyses}

Data from chemical composition, microbiological counts, enzyme activities, and FAA assays were analyzed by one-way ANOVA with a 95\% confidence level. Means were compared by the least significant difference test when significant differences were detected. Principal component (PCA) and nonhierarchical cluster (CA) ( $K$-means) analyses were applied to data from peptide and individual FAA profiles using the covariance matrix (standardization to mean zero and the original variance). The number of clusters for $K$-means analysis was identified in a preliminary test of the original data sets by hierarchical CA. This approach was validated by visual analysis of the density display of the scores after PCA (Hair et al., 1999). All statistical analyses were performed using the SPSS 10.0 software (SPSS Inc., Chicago, IL).

\section{RESULTS}

\section{Cheesemilk Quality and Cheese Composition}

Milk composition remained uniform during both experiments; fat and protein contents ranged from 3.88 to $4.02 \%$ and from 3.22 to $3.29 \%$, respectively. The counts of adventitious lactobacilli in raw milk were between $5 \times 10^{3}$ and $7 \times 10^{3} \mathrm{cfu} / \mathrm{mL}$; after pasteurization they diminished to $<10 \mathrm{cfu} / \mathrm{mL}$. These results indicated that the raw milk was of high microbiological quality and the heat treatment reduced NSLAB level effectively.

The proximate composition and $\mathrm{pH}$ of 30-d-old miniature Cheddar-type cheeses are shown in Table 1. There were no significant differences $(P>0.05)$ in $\mathrm{pH}$, moisture, salt-in-moisture, and protein content between cheeses from both experiments, and all the values were within the normal range expected for conventional Cheddar cheese. Similarly, the acidification rate during manufacture and the final $\mathrm{pH}$ registered after cheddaring were similar in all cheeses from both experiments (results not shown).

\section{Chymosin and Plasmin Activities in Cheeses}

Residual chymosin activity of 30-d-old cheeses made with and without pepstatin or adjunct lactobacilli are presented in Table 2 . The addition of pepstatin into the whey-curd mixture reduced in $95 \%$ the chymosin activity in the cheeses $(P<0.05)$.

Table 1. Gross composition and $\mathrm{pH}$ values of 30-d-old miniature Cheddar-type cheeses from rennet and plasmin experiments ${ }^{1}$

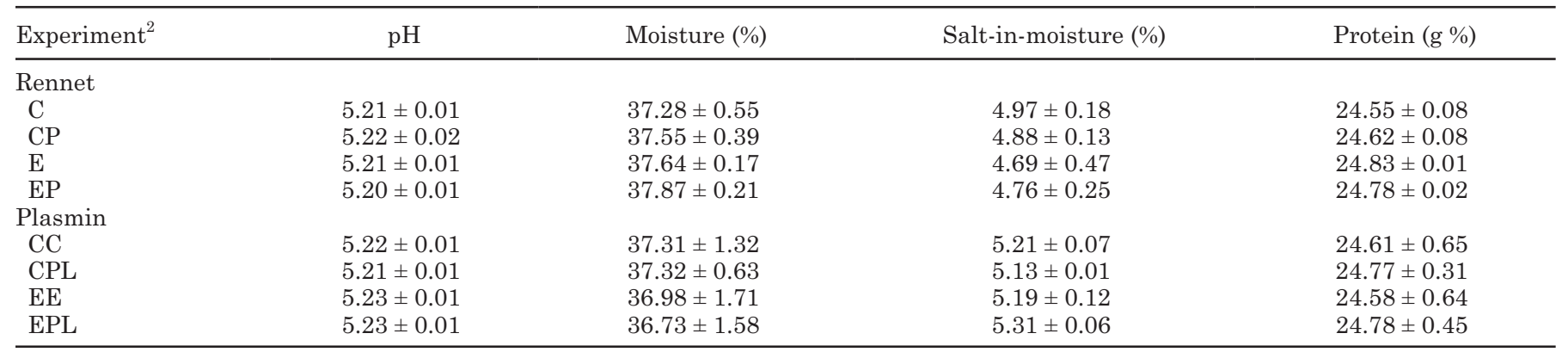

${ }^{1}$ Means $( \pm \mathrm{SD}$ ) of triplicate analyses and 2 cheesemaking trials are presented.

${ }^{2} \mathrm{C}$ and $\mathrm{CC}=$ control cheeses from rennet and plasmin experiments, respectively; $\mathrm{CP}$ and $\mathrm{CPL}=$ control cheeses made with pepstatin and plasmin addition, respectively; $\mathrm{E}$ and $\mathrm{EE}=$ experimental cheeses made with the addition of an adjunct culture of Lactobacillus plantarum I91; EP and EPL = experimental cheeses made with pepstatin and plasmin addition, respectively. 
Table 2. Residual chymosin and plasmin activities of 30-d-old miniature Cheddar-type cheeses from rennet and plasmin experiments $^{1}$

\begin{tabular}{ll}
\hline Experiment $^{2}$ & Enzyme activity \\
\hline Rennet (mmol of product/h· mg of DM) & \\
C & $1.99 \pm 0.13^{\mathrm{a}}$ \\
CP & $0.10 \pm 0.02^{\mathrm{b}}$ \\
E & $2.14 \pm 0.24^{\mathrm{a}}$ \\
EP & $0.13 \pm 0.02^{\mathrm{b}}$ \\
Plasmin (plasmin unit/g of cheese) & $1.60 \pm 0.30^{\mathrm{a}}$ \\
CC & $3.25 \pm 0.40^{\mathrm{b}}$ \\
CPL & $1.62 \pm 0.33^{\mathrm{a}}$ \\
EE & $3.35 \pm 0.62^{\mathrm{b}}$ \\
EPL & \\
\hline
\end{tabular}

${ }^{\mathrm{a}, \mathrm{b}}$ For each experiment, means in the same column with different superscripts differ $(P<0.05)$.

${ }^{1}$ Means $( \pm \mathrm{SD})$ of triplicate analyses and 2 cheesemaking trials are presented.

${ }^{2} \mathrm{C}$ and $\mathrm{CC}=$ control cheeses from rennet and plasmin experiments, respectively; $\mathrm{CP}$ and $\mathrm{CPL}=$ control cheeses made with pepstatin and plasmin addition, respectively; $\mathrm{E}$ and $\mathrm{EE}=$ experimental cheeses made with the addition of an adjunct culture of Lactobacillus plantarum I91; EP and EPL = experimental cheeses made with pepstatin and plasmin addition, respectively.

Table 2 also shows the values of plasmin activity of 30-d-old cheeses made with or without plasmin or adjunct culture. Significant differences $(P<0.05)$ in levels of plasmin were found between cheeses manufactured with and without the addition of plasmin. Plasmin activity in plasmin-treated cheeses was 2 -fold greater than in untreated cheeses. As expected, the introduction of the adjunct culture did not affect residual chymosin or plasmin activities.

\section{Primary Proteolysis}

The urea-PAGE electrophoretograms of the $\mathrm{pH}$ 4.6-insoluble fraction of the cheeses made with and without added pepstatin showed noticeable differences at all ripening times, similar to those previously observed by Shakeel-Ur-Rehman et al. (1998b) and O'Mahony et al. (2005) (data not shown). In the pepstatin-treated cheeses, $a_{\mathrm{s} 1}$-casein remained intact during the ripening period. These results confirm that pepstatin at the level used strongly inhibited residual chymosin activity and, therefore, primary proteolysis. In the cheeses without pepstatin, $a_{\mathrm{s} 1}$-casein was extensively hydrolyzed as ripening progressed, which was evidenced by the production of the peptides $\alpha_{\mathrm{s} 1}-\mathrm{CN}(\mathrm{f} 24-199)$ and $\alpha_{\mathrm{s} 1}-\mathrm{CN}$ (f102-199), both derived from the action of chymosin. Little degradation of $\mathrm{B}$-casein to $\mathrm{Y}_{1^{-}}, \mathrm{Y}_{2^{-}}$, and $\mathrm{Y}_{3}$-caseins was observed during ripening of the 4 types of cheeses in rennet experiment; this hydrolysis is mediated by the action of plasmin (Fox et al., 2000).

No major differences were apparent between cheeses made with and without added plasmin at 1 and $30 \mathrm{~d}$, but differences were observed toward the end of the ripening period (results not shown). In particular, hydrolysis of B-casein was more extensive in the cheeses with plasmin addition, which was evidenced by the breakdown of B-casein and the subsequent production of $\mathrm{Y}_{1^{-}}, \mathrm{Y}_{2^{-}}$, and $\mathrm{Y}_{3}$-caseins. These results are consistent with the greater plasmin activity in the plasmin-treated cheeses and were observed previously by other authors (Farkye and Fox, 1992; Barrett et al., 1999; Somers et al., 2002; Upadhyay et al., 2004). As expected, the addition of plasmin did not increase the breakdown of $a_{\mathrm{s} 1}$-casein, because it is less susceptible to attack by plasmin than B-casein (Fox et al., 2000). In both experiments, no differences in primary proteolysis were evident between cheeses made with adjunct lactobacilli and their respective controls at any stage of ripening.

\section{Starter and Adjunct Cultures and Adventitious Lactobacilli}

The numbers of starter, adjunct, and adventitious lactobacilli in the cheeses made with or without pepstatin or adjunct culture at different sampling times are shown in Figure 1A. Starter lactic acid bacteria counts decreased almost 1 log cycle over the ripening period in all cheeses, regardless of the addition of pepstatin or adjunct culture. On the other hand, adjunct lactobacilli in both experimental cheeses reached high numbers in the cheese $\left(\sim 10^{8} \mathrm{cfu} / \mathrm{g}\right)$ and remained at this level during ripening, whereas the numbers of adventitious lactobacilli in both control cheeses were very low $\left(10^{3}\right.$ $\mathrm{cfu} / \mathrm{g}$ ) for the whole ripening period.

The counts of starter, adventitious, and adjunct lactobacilli in the cheeses made with or without plasmin or adjunct culture during ripening are shown in Figure 1B. The numbers of lactococci decreased by approximately $1.5 \mathrm{log}$ cycles over the course of ripening and, as in the rennet experiment, exhibited a similar trend in all cheeses, independent of the addition of plasmin or adjunct culture. Adjunct lactobacilli were added to the cheesemilk at $10^{4} \mathrm{cfu} / \mathrm{mL}$ but they grew rapidly during manufacture reaching $\sim 10^{6} \mathrm{cfu} / \mathrm{g}$ in both 1-d-old experimental cheeses. From that time onward, a gradual increase in their numbers was observed and they remained at high levels ( $10^{8} \mathrm{cfu} / \mathrm{g}$ of cheese) toward the end of ripening. In the control cheeses made with or without plasmin, adventitious lactobacilli remained at $<10^{3} \mathrm{cfu} / \mathrm{g}$ of cheese during ripening.

\section{Peptide Profiles and Individual Levels of FAA}

Figure 2 shows the peptide profiles of the $\mathrm{pH} 4.6$-soluble fraction of the control and adjunct-treated cheeses made with and without pepstatin at $60 \mathrm{~d}$ of ripening. In 


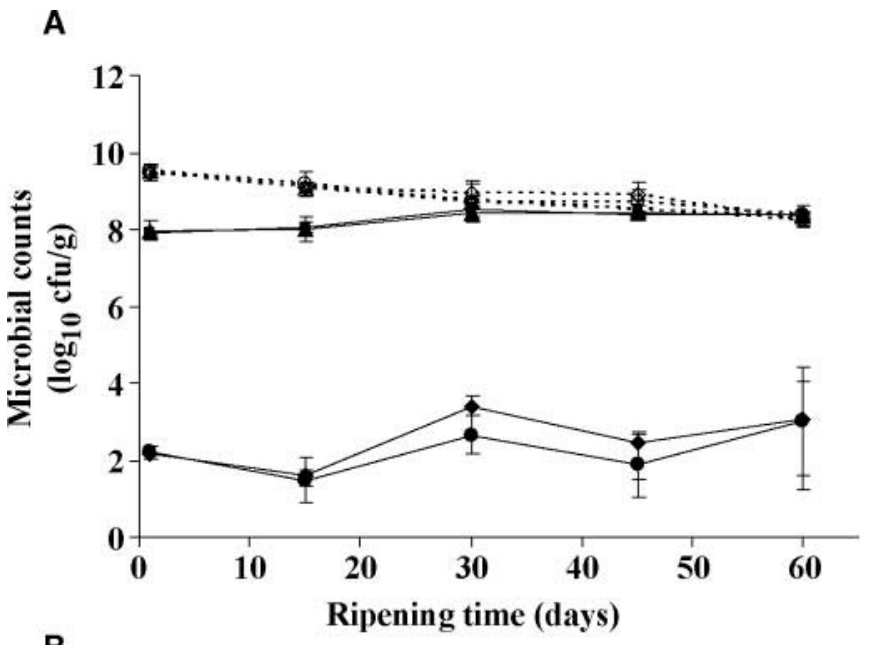

B

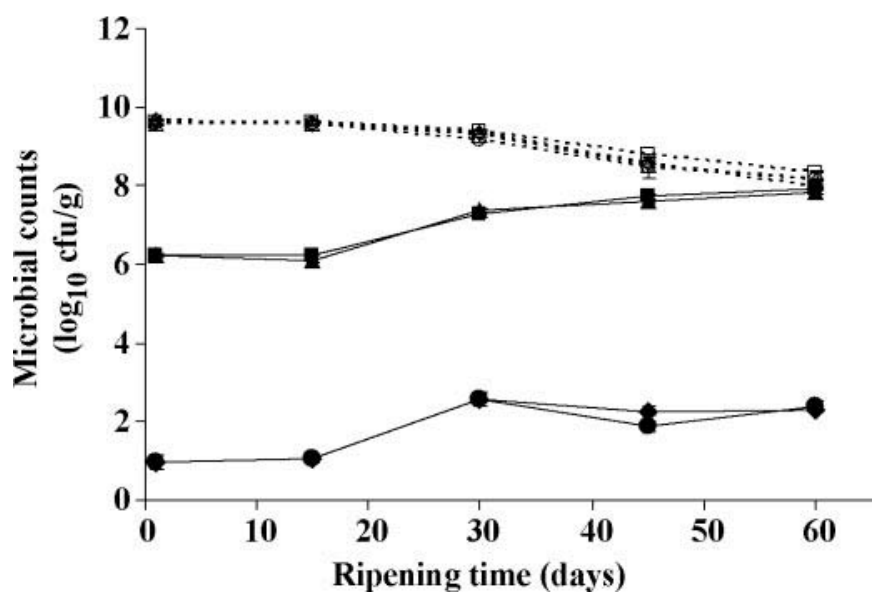

Figure 1. Counts of starter (dotted lines) and lactobacilli (solid lines) in miniature Cheddar-type cheeses from rennet (A) and plasmin (B) experiments, after $1,15,30,45$, and $60 \mathrm{~d}$ of ripening. $\mathrm{C}$ and $\mathrm{CC}(\circ, \bullet)=$ control cheeses; CP and CPL $(\diamond, \bullet)=$ control cheeses made with pepstatin and plasmin addition; $\mathrm{E}$ and $\operatorname{EE}(\Delta, \mathbf{\Delta})=$ experimental cheeses with added Lactobacillus plantarum I91 as adjunct culture; EP and EPL $(\square, \mathbf{\square})=$ experimental cheeses with added $L b$. plantarum I91 as adjunct culture made with pepstatin and plasmin addition, in panels A and B, respectively. The results shown are means of duplicate analyses and 2 cheesemaking trials.

general, the height of the peaks in the chromatograms of all cheeses, especially those made without pepstatin, increased as ripening progressed. Qualitative and quantitative differences in the peptide profiles of the cheeses made with and without pepstatin were observed at all ripening times. Overall, pepstatin-treated cheeses provided simpler chromatograms and lesser amounts of peptides than cheeses without pepstatin. The differences were evident mainly in samples of 30 and $60 \mathrm{~d}$ of ripening in the retention time interval between 25 and $50 \mathrm{~min}$. In particular, the peaks that varied the most between cheeses with and without pepstatin were those eluting at approximately $26,27,33,35$, and $39 \mathrm{~min}$. On

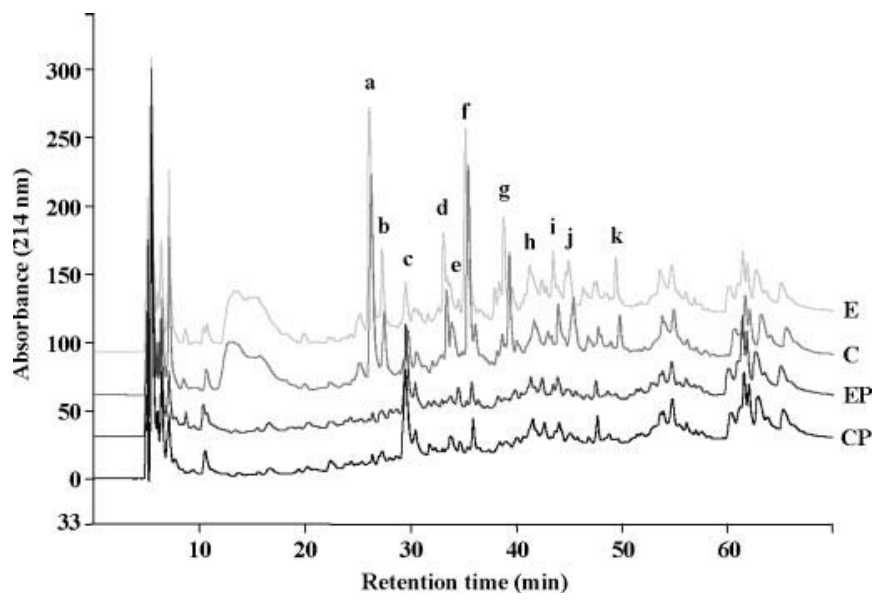

Figure 2. Reverse phase-HPLC peptide profiles of the $\mathrm{pH} 4.6$-soluble fractions of the 60-d-old miniature control and adjunct-treated Cheddar-type cheeses made with or without pepstatin addition. CP and $\mathrm{C}=$ control cheeses made with and without pepstatin, respectively; EP and E = experimental cheeses with added Lactobacillus plantarum I91 as adjunct culture made with and without pepstatin, respectively. Peaks indicated with lowercase letters were used as variables for principal components analysis. The results of one trial are presented.

the other hand, chromatograms of control and adjuncttreated cheeses either made with or without pepstatin showed some quantitative differences, mainly evident at the end of the ripening period.

Eleven peaks, identified as a to $\mathrm{k}$ in Figure 2 were selected by visually comparing the chromatograms, and were used as independent variables for PCA. The peaks selected were those that showed the greatest variation, and not necessarily those with the greatest heights (Pripp et al., 1999). The first 2 principal components (PC) accounted for $97.27 \%$ of the total variation of the data. The loading plot (Figure 3A) revealed that all selected variables exhibited a high influence on PC1, except for peak c, whose impact was considerable only on PC2. Peaks with high influence on PC1 prevailed in the chromatograms of the cheeses made without added pepstatin; these peaks were absent or present at much lower concentrations in the pepstatin-treated cheeses. On the other hand, peak c (with high loading on PC2) was characteristic of the chromatograms of the cheeses made with the addition of pepstatin, at all ripening times. A plot of the distribution of the samples on PC1 and PC2 is shown in Figure 3B. The variability among 1 -d-old cheeses was very low but it increased in cheeses at 30 and $60 \mathrm{~d}$. The influence of both ripening time and type of treatment with or without pepstatin was evident on both PC, but no effect on the variation of the data attributable to the use of the adjunct culture was detected at any ripening time. All 1-d-old cheeses were clustered closely, although they tended to separate 
A

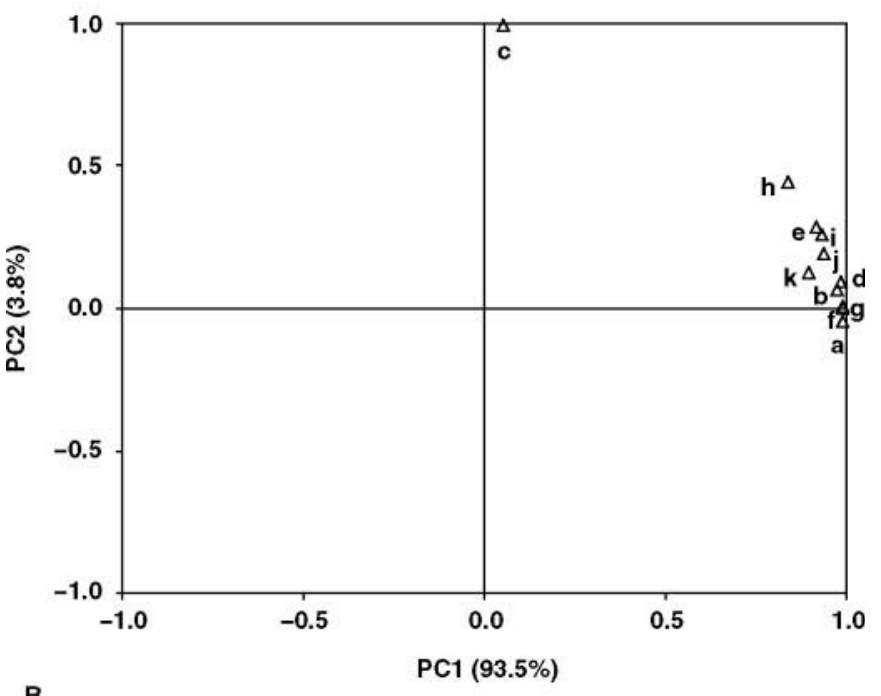

B

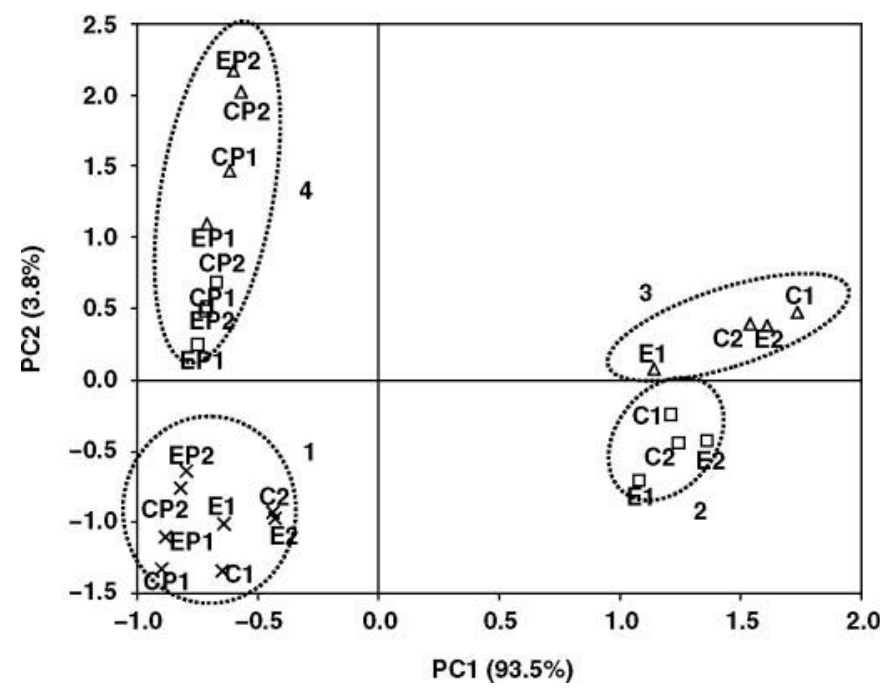

Figure 3. Principal component (PC) analysis of peptide profiles of miniature control and adjunct-treated Cheddar-type cheeses, made with or without pepstatin addition. A) Loading plot of independent variables on PC1 and PC2; B) Score plot on PC1 and PC2 of 1- (×), 30- ( $\square$ ), and 60-d-old $(\Delta)$ cheeses. $\mathrm{CP}$ and $\mathrm{C}=$ control cheeses made with and without pepstatin, respectively; $\mathrm{EP}$ and $\mathrm{E}=$ experimental cheeses with added Lactobacillus plantarum I91 as adjunct culture made with and without pepstatin, respectively. The numbers after cheese type refer to trials 1 and 2 . Ellipses enclose cheese samples in the same cluster as defined by cluster analysis ( $K$-means).

by type of cheese (with or without pepstatin) even at this early time of ripening. Four groups were proposed for CA, which classified the samples as indicated on Figure 3B with ellipses. Cluster 1 contained all 1-dold cheeses, made with or without pepstatin or adjunct lactobacilli. Cluster 2 comprised both 30-d-old control and adjunct-treated cheeses without added pepstatin, whereas the same cheeses but at $60 \mathrm{~d}$ of ripening were grouped in a different cluster (cluster 3). Contrarily, both 30- and 60-d-old control and adjunct-treated cheeses made with pepstatin were grouped together in the same cluster (cluster 4), making clear the inhibition of chymosin-mediated proteolysis, and consequently secondary proteolysis, during cheese ripening.

Figure 4 shows the RP-HPLC peptide profiles of the $\mathrm{pH}$ 4.6-soluble fraction of 60-d-old control and adjunct-treated cheeses made with and without added plasmin. The concentration of most peptides in the chromatograms of the 4 types of cheeses increased during ripening. Comparison of the peptide profiles of cheeses produced with and without plasmin revealed some small quantitative differences after 30 and $60 \mathrm{~d}$ of ripening. Similarly to the rennet experiment, some quantitative differences were observed between chromatograms of control and adjunct-treated cheeses at the end of ripening.

After visual comparison of peptide profiles, 11 peaks (a to $\mathrm{k}$ ) were used as independent variables for PCA. The first 2 PC explained $98.46 \%$ of the total variation. As can be observed in the loading plot (Figure 5A), all selected variables had high correlation with PC1, whereas only peaks f, h, i, j, and k exhibited a relative influence on PC2. Peaks g and e, located on the negative side of PC2, were greater in 30-d-old cheese profiles than in 60-d-old cheese profiles. The rest of the peaks, located on the positive side of $\mathrm{PC} 2$, were predominant in 60-d-old cheeses. Peaks b, c, d, f, and in particular $\mathrm{h}, \mathrm{i}, \mathrm{j}$, and $\mathrm{k}$, which eluted in the hydrophobic region of the chromatograms, were found to be slightly greater in the plasmin-treated cheeses. The score plot of the samples at 1, 30, and $60 \mathrm{~d}$ of ripening is shown in Figure 5B. Little variability between cheeses was observed at all ripening times. No grouping of samples with regard to the different treatments applied (addition of plasmin or adjunct lactobacilli) was detected on both $\mathrm{PC} 1$ and $\mathrm{PC} 2$ axes at all ripening times. On the other hand, cheeses were distributed according to ripening time on PC2, whereas only 1-d-old cheeses were separated from the rest along $\mathrm{PC} 1$ axis. Cluster analysis confirmed these results as it distributed the samples in the 3 clusters proposed according to the ripening time: cheese samples of 1-, 30-, and 60-d-old cheeses were grouped in clusters 1,2, and 3, respectively, regardless of the cheese plasmin activity or the presence of the adjunct culture (Figure 5B).

Individual amounts of FAA in the cheeses made with and without pepstatin or adjunct lactobacilli at 1 and 60 $\mathrm{d}$ of ripening are shown in Figure 6 . The content of most amino acids increased $(P<0.05)$ with ripening time in all cheeses, except for pepstatin-treated control cheeses (CP) in which only a few amino acids showed a significant increase as ripening progressed. Control and ex- 


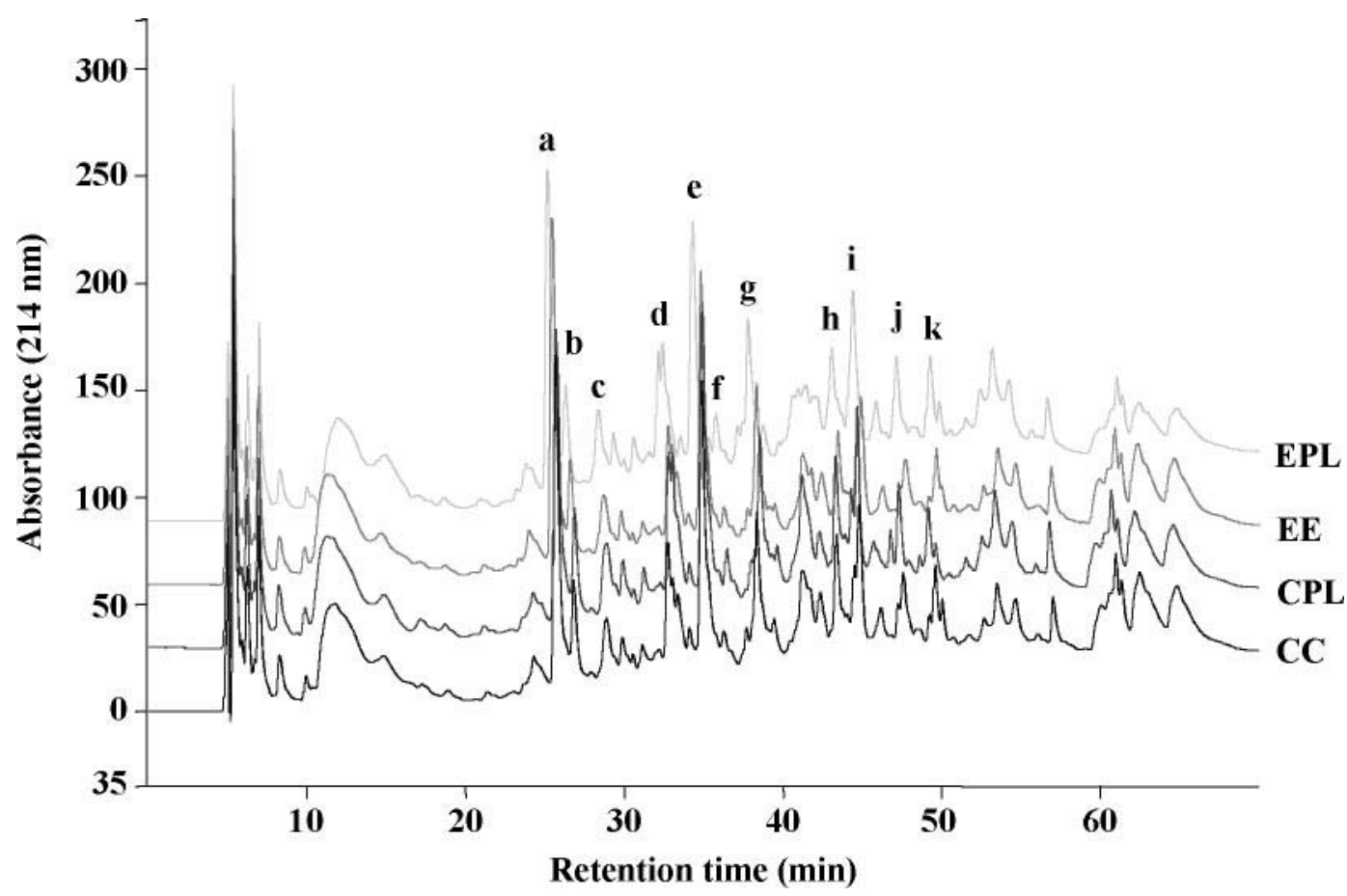

Figure 4. Reverse phase-HPLC peptide profiles of the $\mathrm{pH} 4.6$-soluble fractions of the 60-d-old miniature control and adjunct-treated Cheddar-type cheeses made with or without plasmin addition. CPL and CC = control cheeses made with and without plasmin, respectively; EPL and EE = experimental cheeses with added Lactobacillus plantarum I91 as adjunct culture made with and without plasmin, respectively. Peaks indicated with lowercase letters were use as variables for principal components analysis. The results of one trial are presented.

perimental pepstatin-treated cheeses had significantly $(P<0.05)$ lower levels of total FAA than control and experimental cheeses made without added pepstatin, respectively, after $60 \mathrm{~d}$ of ripening. On the other hand, adjunct-treated cheeses made with or without added pepstatin had significantly $(P<0.05)$ greater levels of total FAA than their respective control cheeses after 60 $\mathrm{d}$ of ripening. Furthermore, the increase in the content of total FAA in the adjunct-treated cheeses compared with their respective controls was similar ( 1.6 times), regardless of the activity of residual chymosin. In addition, the content of total FAA between adjunct-treated cheeses made with added pepstatin (EP) and control cheeses made without pepstatin (C) did not differ significantly $(P>0.05)$.

The major individual FAA in 60-d-old control and adjunct-treated cheeses made without pepstatin were serine, glutamate, proline, lysine, leucine, and phenylalanine, which accounted for about $70 \%$ of the total FAA, whereas glutamate, histidine, threonine, proline, lysine, and leucine predominated in 60-d-old control and experimental cheeses with added pepstatin, in which they accounted for 68 and $63 \%$ of the total FAA, respectively. Overall, the levels of serine, glycine, histidine, threonine, alanine, valine, methionine, lysine, and leucine were greater in the adjunct-treated cheeses compared with their respective controls at $60 \mathrm{~d}$ of ripening $(P<0.05)$. On the other hand, pepstatin-treated cheeses exhibited significantly lower concentrations ( $P$ $<0.05$ ) of serine, glycine, arginine, valine, leucine, and phenylalanine than cheeses without pepstatin.

The individual concentrations of each amino acid in the cheeses at 1 and $60 \mathrm{~d}$ of ripening were used as variables for PCA and CA to detect grouping of samples based on their individual FAA profiles: PC1 and PC2 explained 77.7 and $10.9 \%$ of the total variation, respectively. The amino acids most correlated with $\mathrm{PC} 1$ were serine, glycine, histidine, threonine, valine, methionine, lysine, leucine, and phenylalanine, whereas isoleucine and, to a lesser extent, proline, alanine, histidine, lysine, and methionine exhibited a relative influence on PC2 (Figure 7A). The score plot (Figure 7B) shows grouping of samples according to cheese types (made with or without pepstatin or adjunct culture) on both $\mathrm{PC}$ and based on ripening time on PC1. Four clusters were proposed for CA, which classified the samples as follows: cluster 1 comprised all 1-d-old cheeses, regardless of the addition of pepstatin or adjunct lactobacilli, as well as of one 60-d-old pepstatin-treated control cheese. Cluster 2 consisted of one control and both adjunct-treated cheeses with added pepstatin of $60 \mathrm{~d}$ of ripening. Clusters 3 and 4 enclosed 60-d-old control 
and adjunct-treated cheeses without pepstatin, respectively (Figure 7B).

Figure 8 shows the individual FAA profiles of the cheeses made with and without added plasmin or adjunct lactobacilli at 1 and $60 \mathrm{~d}$ of ripening. The amount of total FAA increased with ripening time in all cheeses $(P<0.05)$. There were not significant differences in the total content of FAA between cheeses made with or without added plasmin, indicating that the increase in plasmin activity did not improve the formation of amino acids. According to our results, the main FAA in 60-dold cheeses were serine, glutamate, proline, lysine, leucine, and phenylalanine, which agrees with the results of the previous experiment for cheeses made without pepstatin. In contrast to the trend observed for the rennet experiment, the total content of FAA in the cheeses made with or without adjunct lactobacilli was similar, which could be attributed to the lower initial dose of the adjunct culture in plasmin experiment. There were no significant differences in the levels of most amino acids among cheeses because of the treatments applied (addition of plasmin or adjunct lactobacilli), except for glycine and arginine, after $60 \mathrm{~d}$ of ripening.

Principal components 1 and 2 explained 78.8 and $10.0 \%$ of the global variation of the data, respectively. The amino acids most correlated with $\mathrm{PC} 1$ were serine, glycine, arginine, threonine, alanine, valine, methionine, lysine, leucine, phenylalanine, histidine, proline, aspartate, and glutamate, whereas tyrosine and, to a lesser extent, isoleucine and aspartate had a relative effect on PC2 (Figure 9A). As can be observed in the score plot (Figure 9B), PC1 separated the samples based on ripening time, whereas there was a tendency to group cheeses made with or without lactobacilli adjunct on PC2 after $60 \mathrm{~d}$ of ripening. On the other hand, some variability among 1-d-old cheeses from different trials was observed. Of the 4 clusters proposed, clusters 1 and 2 were composed of 1 -d-old cheeses from trials 1 and 2, respectively. Cluster 3 and 4 consisted of $60-\mathrm{d}$ old control and adjunct-treated cheeses, respectively, independent of the level of plasmin in the cheeses (Figure 9B).

\section{DISCUSSION}

The addition of pepstatin, plasmin, or adjunct culture neither introduced changes on cheese composition, nor interfered with the acidification by the starter. Milesi et al. (2008) previously reported that $L b$. plantarum I91 added to the cheesemilk at a high level did not contribute to acidification of the curd/cheese during cheese manufacture and ripening. On the other hand, Shakeel-Ur-Rehman et al. (1998b) reported no compositional differences between miniature control cheeses and cheeses containing $7.5,15.0$, or $30.0 \mu \mathrm{mol} / \mathrm{L}$ pepstatin. In contrast, O'Mahony et al. (2005) reported that the moisture content of Cheddar cheeses made at the pilot-plant scale decreased with increasing levels of pepstatin and ascribed these changes to greater syneresis of the curd in the presence of pepstatin; these authors used lower concentrations of pepstatin $(0.1,1.0$, and $10.0 \mu \mathrm{mol})$. As for plasmin-treated cheeses, Farkye and Landkammer (1992) reported greater moisture
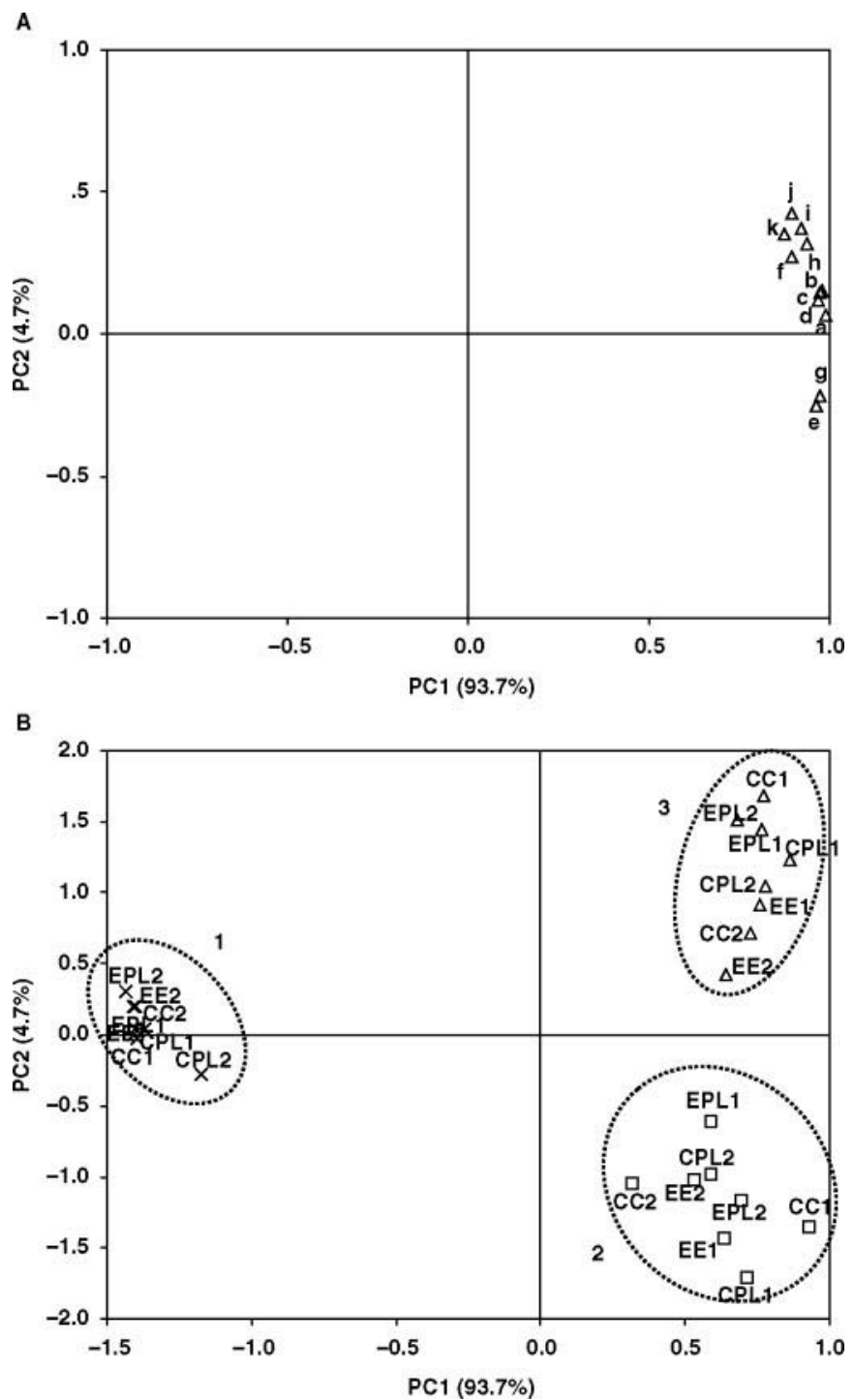

Figure 5. Principal component (PC) analysis of peptide profiles of miniature control and adjunct-treated Cheddar-type cheeses, made with or without plasmin addition. A) Loading plot of independent variables on $\mathrm{PC} 1$ and $\mathrm{PC} 2$; B) score plot on $\mathrm{PC} 1$ and $\mathrm{PC} 2$ of 1- $(\times)$, 30- ( $\square$ ), and 60-d-old $(\Delta)$ cheeses. CPL and CC $=$ control cheeses made with and without plasmin, respectively; EPL and EE = experimental cheeses with added Lactobacillus plantarum I91 as adjunct culture made with and without plasmin, respectively. The numbers after cheese type refer to trials 1 and 2. Ellipses enclose cheese samples in the same cluster as defined by cluster analysis ( $K$-means). 


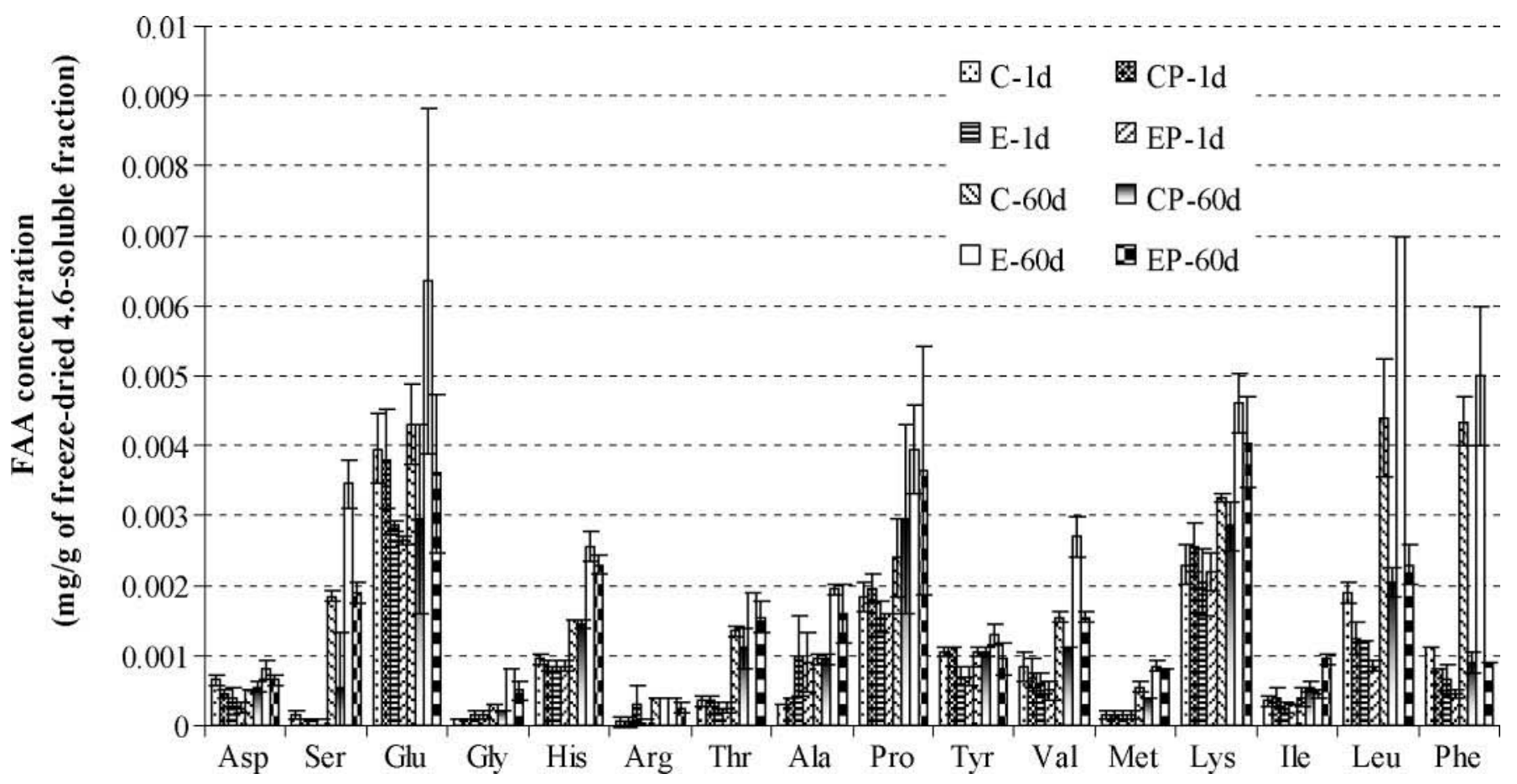

Figure 6. Individual free amino acid (FAA) profiles of miniature control and adjunct-treated Cheddar-type cheeses, made with and without pepstatin addition, after 1 and $60 \mathrm{~d}$ of ripening. $\mathrm{CP}$ and $\mathrm{C}=$ control cheeses made with and without pepstatin, respectively; EP and $\mathrm{E}=$ experimental cheeses with added Lactobacillus plantarum I91 as adjunct culture made with and without pepstatin, respectively.

content in cheeses containing a 6 -fold increase in plasmin activity compared with the control and attributed this phenomenon to a greater ability of the proteins and peptides in the curd to bind water because of the hydrolytic activity of plasmin. In this study, however, the increase in plasmin activity was not linked to an increase in moisture content, which agrees with other studies (Barrett et al., 1999; Upadhyay et al., 2004).

In agreement with the findings of Shakeel-Ur-Rehman et al. (1998b), the pepstatin level $(15 \mu \mathrm{mol} / \mathrm{L})$ used in this study was effective at inhibiting the residual chymosin in the cheeses. On the other hand, the addition of plasmin solution obtained by incubation of plasminogen and urokinase also proved to be an effective way to increase plasmin activity in the final products. The changes in plasmin activity were not as great as in the rennet experiment for chymosin residual activity, but were similar to those reported in previous studies on plasmin activation. Barrett et al. (1999) added increasing concentrations $(0.25,0.5,1$, or 5 units $/ \mathrm{mL})$ of urokinase to cheesemilk and reported an enhancement of plasmin activity in Cheddar cheese of about 2- and 4 -fold when 1 and 5 units urokinase $/ \mathrm{mL}$ of milk were added, respectively. Upadhyay et al. (2004) manufactured Cheddar cheese with increasing concentration $(0.1,0.25$, or $0.50 \%)$ of streptokinase (a plasminogen activator produced from Streptococcus uberis), and plasmin activity increased about 4 times compared with the control when the greatest concentration of streptokinase was used.

The inhibition of residual chymosin activity caused an important reduction in the extent of primary proteolysis, evidenced by the absence of $\alpha_{\mathrm{s} 1}$-casein hydrolysis, while the increase of plasmin activity resulted in an acceleration of primary proteolysis, characterized by a greater formation of breakdown products of B-casein. On the other hand, the addition of the adjunct culture did not contribute to primary proteolysis. This was not surprising, as most adjunct lactobacilli strains tested to date have shown similar behavior regarding primary proteolysis (McSweeney et al., 1994; Swearingen et al., 2001; Di Cagno et al., 2006). It is known that mesophilic lactobacilli from NSLAB source generally possess low proteolytic activity, although they have shown diverse and sometimes high peptidolytic abilities (Peláez and Requena, 2005; Bude-Ugarte et al., 2006).

Starter populations presented a similar evolution during ripening of the 4 types of cheeses from both experiments, made with or without pepstatin, plasmin, or adjunct culture. This trend indicated that the addition of adjunct lactobacilli, pepstatin, or plasmin did not influence the growth and survival of starter bacteria. On the other hand, the decrease in residual chymosin activity and therefore, the inhibition of rennet-mediated primary proteolysis, did not influence the rate and extent of lactobacilli growth, as lactoba- 
cilli grew to the same level in cheeses made with or without pepstatin addition. Hence, the growth of the studied adjunct culture appears not to be dependent on the amount of peptides and FAA available in the cheese matrix. These observations indicated that the relatively poor pool of peptides and FAA available in the pepstatin-treated cheeses was sufficient to sustain the growth of lactobacilli at the same level as in the cheeses made without added pepstatin. Similarly, the

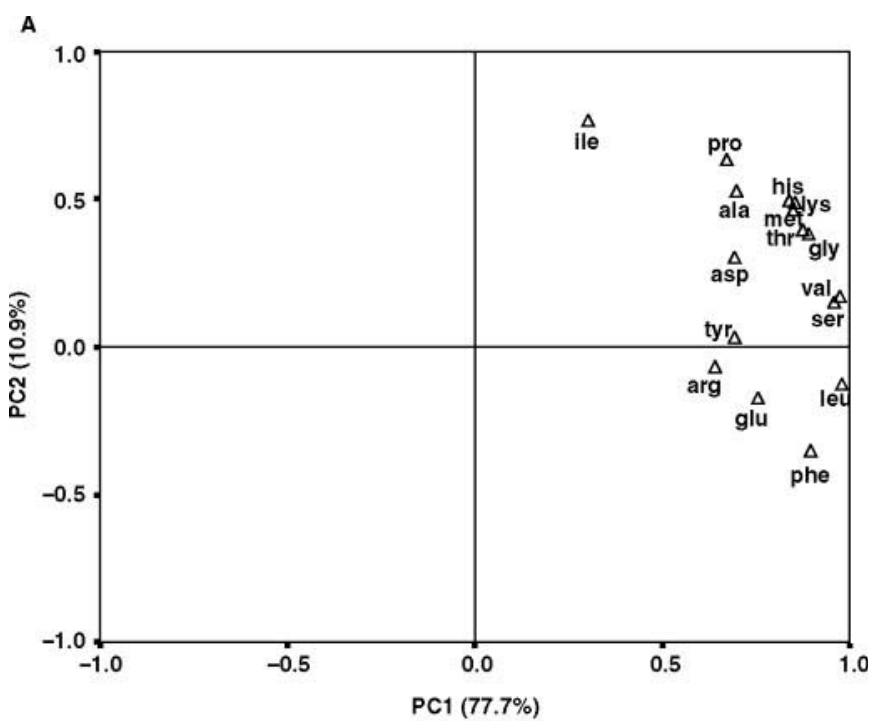

B

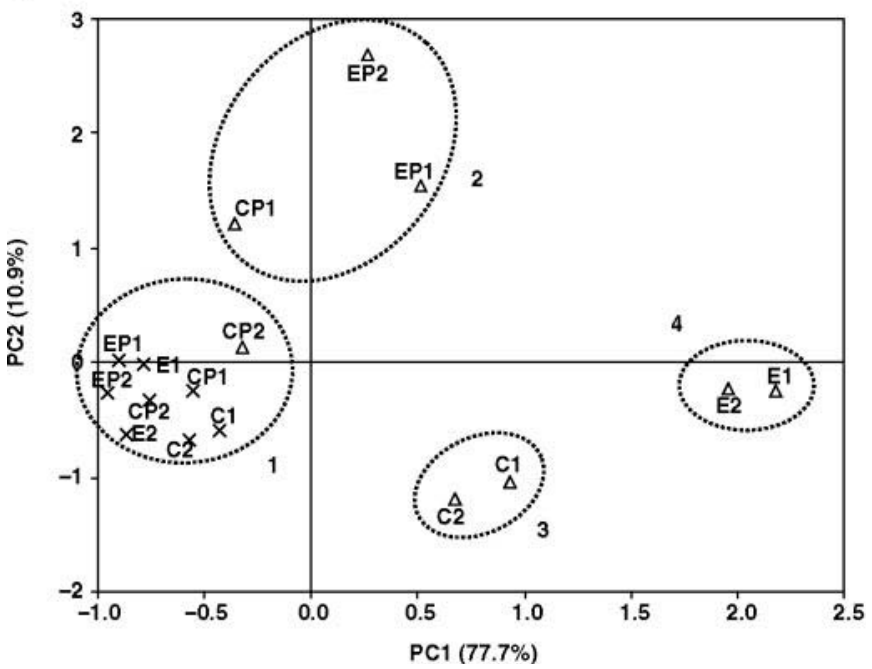

Figure 7. Principal component (PC) analysis of data from individual free amino acid profiles of miniature control and adjunct-treated Cheddar-type cheeses, made with or without pepstatin addition. A) Loading plot of independent variables on PC1 and PC2. B) Score plot on PC1 and PC2 of 1- $(\times)$ and $60-d$-old $(\Delta)$ cheeses. $\mathrm{CP}$ and $\mathrm{C}=$ control cheeses made with and without pepstatin, respectively; EP and E = experimental cheeses with added Lactobacillus plantarum I91 as adjunct culture made with and without pepstatin, respectively. The numbers after cheese type refer to trials 1 and 2. Ellipses enclose cheese samples in the same cluster as defined by cluster analysis ( $K$-means). increase in cheese plasmin activity, and consequently the enhancement of plasmin-mediated primary proteolysis, did not affect the rate and extent of lactobacilli growth, as lactobacilli grew to the same level in cheeses made with or without plasmin.

Cheeses made with added pepstatin exhibit much lower concentrations of peptides as evidenced by HPLC profiles. Shakeel-Ur-Rehman et al. (1998b) and O'Mahony et al. (2005) reported that some of the peptides observed in the chromatograms are produced by the sequential action of coagulant and starter on $\alpha_{\mathrm{s} 1}$-casein. As no degradation of $\alpha_{\mathrm{s} 1}$-casein in pepstatintreated cheeses occurred, very low amounts of small or intermediate-sized peptides were produced. As for the plasmin experiment, no major differences were detected in the peptide profiles of cheeses made with or without plasmin. Upadhyay et al. (2004) reported that the concentrations of peptides that eluted between 55 and 60 min in the chromatograms of $70 \%$ ethanol-soluble fraction were slightly greater in the streptokinase-treated cheeses compared with the controls, and that they increased with increasing levels of added streptokinase. Barrett et al. (1999) also found greater concentrations of hydrophobic peptides eluting between 52 and $58 \mathrm{~min}$ in the chromatograms of ethanol-soluble subfraction of the aqueous extract of cheeses containing $5 \mathrm{U} / \mathrm{mL}$ of urokinase with respect to the control. In this study, the increase in cheese plasmin activity did not cause a noticeable increase in the concentration of hydrophobic peptides. It has been reported that peptides eluting in the hydrophobic region of RP-HPLC chromatograms correspond to components of the protease peptone fraction, mostly degradation products from plasmin activity on B-casein (Kelly and O'Donnell, 1998; Upadhyay et al., 2004).

Although quantitative differences were evident between peptide profiles of control and adjunct-treated cheeses in both experiments, cluster analysis indicated that these types of samples were grouped together, in contrast to previous reports for this Lb. plantarum strain (Milesi et al., 2008). In the rennet experiment, this was probably because the variation among peptide profiles was mainly explained by the differences in chymosin activity; changes in this factor probably masked the subtler differences caused by the action of the adjunct culture. For the plasmin experiment, only ripening time affected peptide profiles sufficiently to be separated by CA. Several authors found no or little effect of lactobacilli adjunct cultures on the peptide profiles of several cheese varieties (McSweeney et al., 1994; Hynes et al., 2001).

Pepstatin-treated cheeses exhibited lower concentrations of total FAA than those made without added pepstatin, which is in line with the results reported by 


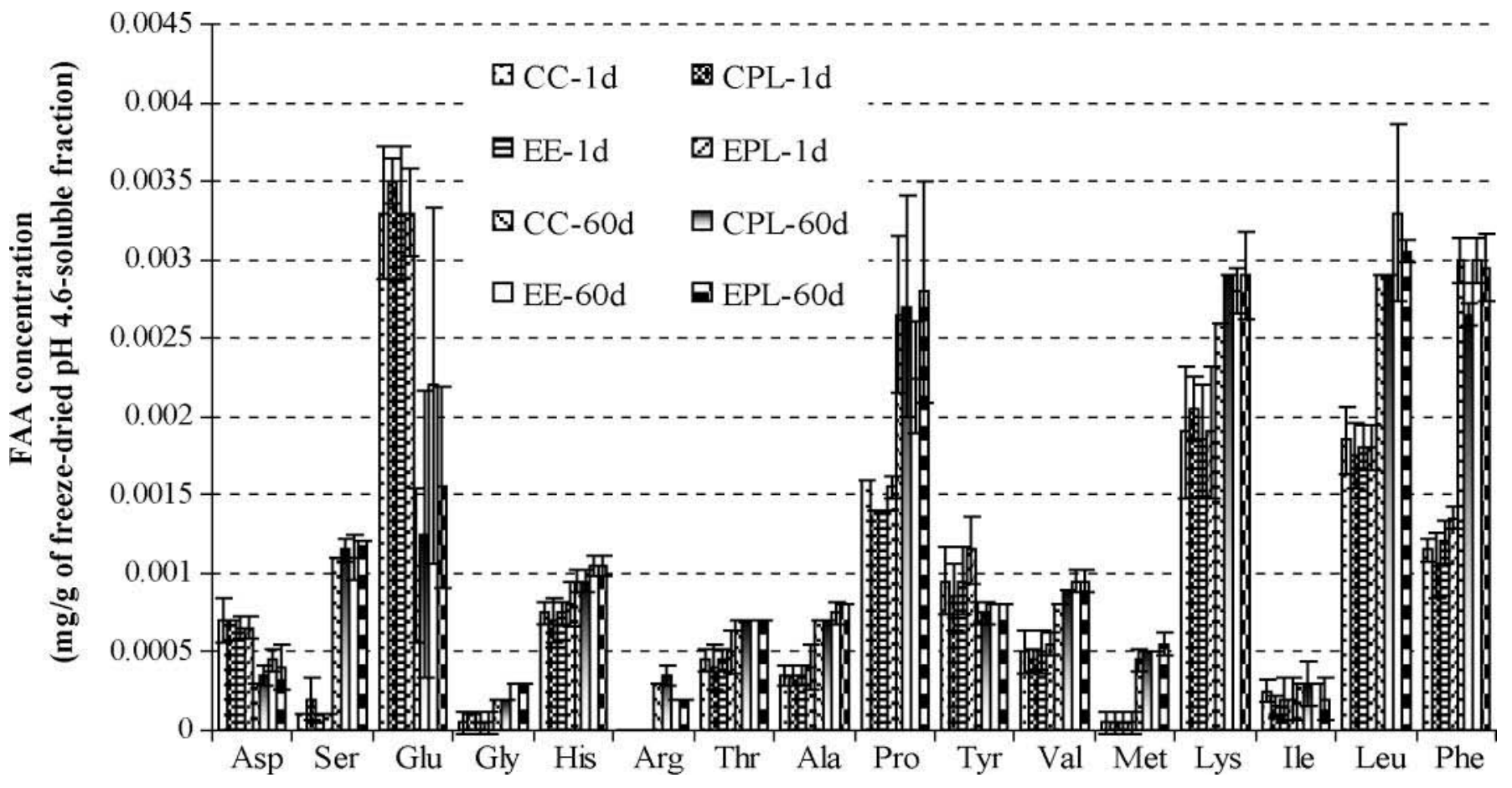

Figure 8. Individual free amino acid (FAA) profiles of miniature control and adjunct-treated Cheddar-type cheeses made with and without plasmin addition, after 1 and $60 \mathrm{~d}$ of ripening. $\mathrm{CPL}$ and $\mathrm{CC}=$ control cheeses made with and without plasmin, respectively; EPL and EE $=$ experimental cheeses with added Lactobacillus plantarum I91 as adjunct culture made with and without plasmin, respectively.

Shakeel-Ur-Rehman et al. (1998b) and O'Mahony et al. (2005) who found that FAA content decreased with increasing levels of pepstatin addition. Rennet-free cheeses obtained by a different method showed lower concentrations of FAA compared with their controls (Lane et al., 1997a). On the other hand, the levels of total FAA in both adjunct-treated cheeses made with or without added pepstatin were greater than in their respective control cheese, which suggests that the peptidases of $L b$. plantarum I91 contributed significantly to the release of FAA during ripening. Increase in the level of total FAA in cheeses containing different strains of lactobacilli as adjunct culture have been previously reported by other authors (Swearingen et al., 2001; Hynes et al., 2003; Di Cagno et al., 2006). More evidence that supported the ability of $L b$. plantarum I91 in the formation of FAA was the fact that addition of this adjunct lactobacillus to experimental pepstatin-treated cheeses increased the content of total FAA enough to make them similar to control cheeses made without pepstatin. On the other hand, the fact that the increase in the content of total FAA in the adjunct-treated cheeses was similar to that in the respective controls indicated that the extent of primary proteolysis and the availability of peptides coming from the action of chymosin on caseins did not influence the peptidolytic activity of $L b$. plantarum I91.
For the plasmin experiment, the increase in cheese plasmin activity did not improve the formation of a mino acids. These results are in agreement with those reported by Upadhyay et al. (2004) who found no significant differences in the concentration of total FAA between cheeses made with increasing levels of streptokinase and the control. These authors reported that plasmin has little effect on the production of FAA but is responsible for the production of intermediate-sized peptides, which are precursors for the formation of amino acids by the action of starter peptidases. Farkye and Fox (1992) and O'Farrell et al. (2002) observed a similar trend: in their studies, increasing plasmin activity in cheese did not affect the levels of phosphotungstic acidsoluble nitrogen, which represents mainly amino acids. Although no difference in the total content of FAA was observed between control and adjunct-treated cheeses, PCA and CA distributed them into separate groups, indicating that the addition of $L b$. plantarum I91 had an effect on secondary proteolysis, as it modified the individual FAA profile.

\section{CONCLUSIONS}

Primary proteolysis due to chymosin and plasmin activity did not influence the growth and the biochemical activities of adventitious or adjunct lactobacilli in 
A

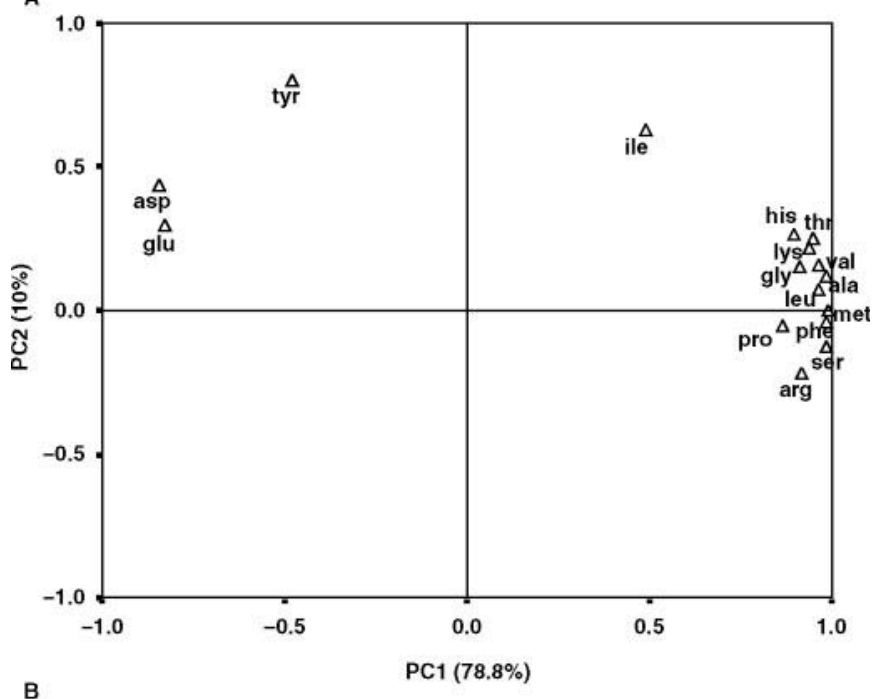

B

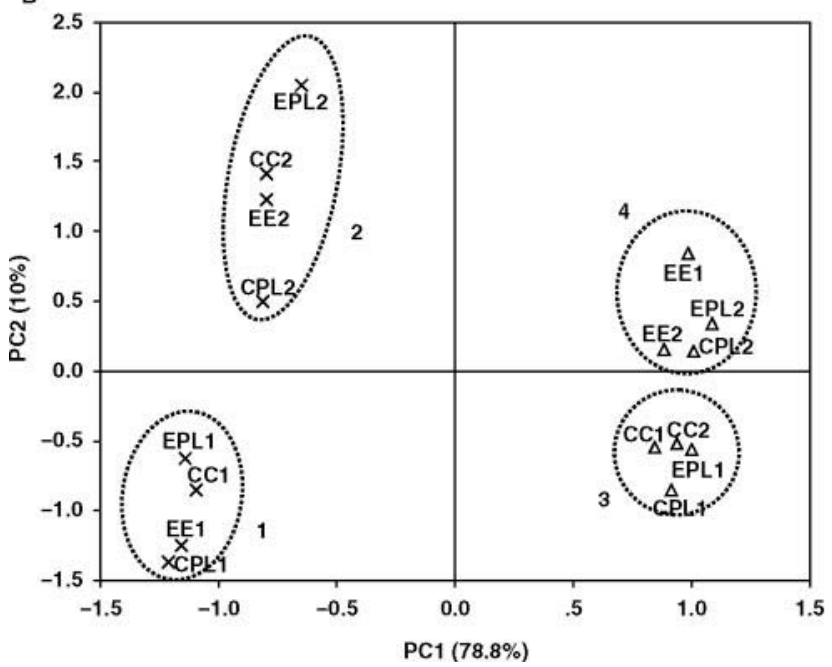

Figure 9. Principal component (PC) analysis of data from individual free amino acid profiles of miniature control and adjunct-treated Cheddar-type cheeses, made with or without plasmin addition. A) Loading plot of independent variables on PC1 and PC2; B) score plot on PC1 and PC2 of 1- $(\times)$ and 60-d-old $(\Delta)$ cheeses. CPL and CC $=$ control cheeses made with and without plasmin, respectively; EPL and $\mathrm{EE}=$ experimental cheeses with added Lactobacillus plantarum I91 as adjunct culture made with and without plasmin, respectively. The numbers after cheese type refer to trials 1 and 2. Ellipses enclose cheese samples in the same cluster as defined by cluster analysis (K-means).

miniature Cheddar-type cheeses, indicating that it does not represent a limiting factor for the development and proteolytic-peptidolytic activities of lactobacilli in the studied cheese model. Unlike previous studies that suggest that proteolytic activity of the starter lactic acid bacteria can increase the growth and peptidolysis of NSLAB and Lactobacillus adjunct cultures in cheese, we found that the proteolysis due to nonmicrobial proteases, usually added (rennet) or naturally present (plasmin) in the cheesemilk, does not improve the growth of lactobacilli or their activity under the conditions studied.

\section{ACKNOWLEDGMENTS}

This work was partially financed by the Programme Alßan, a European Union Programme of High Level Scholarships for Latin America (Scholarship No. E05D050374AR). María Mercedes Milesi would like to thank the Programme Alßan for the awarding of the scholarship. The authors also acknowledge the financial support from Agencia Nacional de Promoción Científica y Tecnológica (Proyecto PICTO 09-13227) and Consejo Nacional de Investigaciones Científicas y Técnicas (CONICET).

\section{REFERENCES}

Adamberg, K., M. Antonsson, F. K. Vogensen, E. W. Nielsen, S. Kask, P. L. Møller, and Y. Ardö. 2005. Fermentation of carbohydrates from cheese sources by non-starter lactic acid bacteria isolated from semi-hard Danish cheese. Int. Dairy J. 15:873-882.

Barrett, F. M., A. L. Kelly, P. L. H. McSweeney, and P. F. Fox. 1999. Use of exogenous urokinase to accelerate proteolysis in Cheddar cheese during ripening. Int. Dairy J. 9:421-427.

Bude-Ugarte, M., D. Guglielmotti, G. Giraffa, J. A. Reinheimer, and E. Hynes. 2006. Non-starter lactobacilli from Argentinean cheeses. J. Food Prot. 69:2983-2991.

Christiansen, P., E. W. Nielsen, F. K. Vogensen, C. H. Brogren, and Y. Ardö. 2006. Heat resistance of Lactobacillus paracasei isolated from semi-hard cheese made of pasteurized milk. Int. Dairy J. 16:1196-1204.

Di Cagno, R., M. De Angelis, V. K. Upadhyay, P. L. H. McSweeney, F. Minervini, G. Gallo, and M. Gobetti. 2003. Effect of proteinases of starter bacteria on the growth and proteolytic activity of Lactobacillus plantarum DPC2741. Int. Dairy J. 13:145-157.

Di Cagno, R., M. Quinto, A. Corsetti, F. Minervini, and M. Gobbetti. 2006. Assessing the proteolytic and lipolytic activities of single strains of mesophilic lactobacilli as adjunct cultures using a Caciotta cheese model system. Int. Dairy J. 16:119-130.

Farkye, N., and P. F. Fox. 1992. Contribution of plasmin to Cheddar cheese ripening: Effect of added plasmin. J. Dairy Res. 59:209216.

Farkye, N. Y., and C. F. Landkammer. 1992. Milk plasmin activity influence on Cheddar cheese quality during ripening. J. Food Sci. 57:622-624.

Folkertsma, B., P. F. Fox, and P. L. H. McSweeney. 1996. Accelerated ripening of Cheddar cheese at elevated temperatures. Int. Dairy J. 6:1117-1134.

Fox, P. F. 1963. Potentiometric determination of salt in cheese. J. Dairy Sci. 46:744-745.

Fox, P. F., T. P. Guinee, T. M. Cogan, and P. L. H. McSweeney. 2000. Biochemistry of Cheese Ripening. Pages 236-281 in Fundamentals of Cheese Science. P. F. Fox, ed. Aspen Publishers Inc., Frederick, MD.

Fox, P. F., J. Law, P. L. H. McSweeney, and J. Wallace. 1993. Biochemistry of cheese ripening. Pages 389-438 in Cheese: Chemistry, Physics and Microbiology. Vol. 1. P. F. Fox, ed. Chapman \& Hall, London, UK.

Fox, P. F., and L. Stepaniak. 1993. Enzymes in cheese technology. Int. Dairy J. 3:509-530.

Hair, J. F., R. E. Anderson, R. L. Tatham, and W. C. Black. 1999. Análisis Cluster. Pages 491-533 in Análisis Multivariante. Prentice Hall Iberia, Madrid, Spain. 
Hurley, M. J., B. M. O'Driscoll, A. L. Kelly, and P. L. H. McSweeney. 1999. Novel assay for the determination of residual coagulant activity in cheese. Int. Dairy J. 9:553-558.

Hynes, E., C. Bach, G. Lamberet, J. C. Ogier, O. Son, and A. Delacroix-Buchet. 2003. Contribution of starter lactococci and adjunct lactobacilli to proteolysis, volatile profiles and sensory characteristics of washed-curd cheese. Lait 83:31-43.

Hynes, E., J. C. Ogier, and A. Delacroix-Buchet. 2001. Proteolysis during ripening of miniature washed-curd cheeses manufactured with different strains of starter bacteria and a Lactobacillus plantarum adjunct culture. Int. Dairy J. 11:587-597.

International Dairy Federation (IDF). 1982. Determination of the total solid content (cheese and processed cheese). IDF Standard 4A. IDF, Brussels, Belgium.

International Dairy Federation (IDF). 1993. Milk. Determination of the nitrogen (Kjeldahl method) and calculation of the crude protein content. IDF Standard 20B. IDF, Brussels, Belgium.

Jordan, K. N., and T. M. Cogan. 1999. Heat resistance of Lactobacillus spp. isolated from Cheddar cheese. Lett. Appl. Microbiol. 29:136-140.

Kelly, A. L., and H. J. O’Donnell. 1998. Composition, gel properties and microstructure of Quarg as affected by processing parameters and milk quality. Int. Dairy J. 8:295-301.

Lane, C. N., P. F. Fox, D. E. Johnston, and P. L. H. McSweeney. 1997a. Contribution of coagulant to proteolysis and textural changes in Cheddar cheese during ripening. Int. Dairy J. 7:453-464.

Lane, C. N., P. F. Fox, E. M. Walsh, B. Folkertsma, and P. L. H McSweeney. 1997b. Effect of compositional and environmental factors on the growth of indigenous non-starter lactic acid bacteria in Cheddar cheese. Lait 77:561-573.

Martley, F. G., and V. L. Crow. 1993. Interactions between nonstarter microorganisms during cheese manufacture and ripening. Int. Dairy J. 3:461-483.

McSweeney, P. L. H., P. F. Fox, J. A. Lucey, R. N. Jordan, and T. M. Cogan. 1993. Contribution of the indigenous microflora to the maturation of Cheddar cheese. Int. Dairy J. 3:613-634.

McSweeney, P. L. H., E. M. Walsh, P. F. Fox, T. M. Cogan, F. D. Drinan, and M. Castelo-Gonzalez. 1994. A procedure for the manufacture of Cheddar cheese under controlled bacteriological conditions and the effect of adjunct lactobacilli on cheese quality. Ir. J. Agric. Food Res. 33:183-192.

Milesi, M. M., P. L. H. McSweeney, and E. R. Hynes. 2008. Viability and contribution to proteolysis of an adjunct culture of Lactobacillus plantarum in two model cheese systems: Cheddar cheese-type and soft-cheese type. J. Appl. Microbiol. doi:doi:10.1111/j.13652672.2008.03813.x

O'Farrell, I. P., J. J. Sheehan, M. G. Wilkinson, D. Harrington, and A. L. Kelly. 2002. Influence of addition of plasmin or mastitic milk to cheesemilk on quality of smear-ripened cheese. Lait $82: 305-316$

O'Mahony, J. A., J. A. Lucey, and P. L. H. McSweeney. 2005. Chymosin-mediated proteolysis, calcium solubilization, and texture development during the ripening of Cheddar cheese. J. Dairy Sci. 88:3101-3114.
Peláez, C., and T. Requena. 2005. Exploiting the potential of bacteria in the cheese ecosystem. Int. Dairy J. 15:831-844.

Peterson, S. D., and R. T. Marshall. 1990. Nonstarter lactobacilli in Cheddar cheese: A Review. J. Dairy Sci. 73:1395-1410.

Pripp, A. H., Shakeel-Ur-Rehman, P. L. H. McSweeney, and P. F. Fox. 1999. Multivariate statistical analysis of peptide profiles and free amino acids to evaluate effects of single-strain starters on proteolysis in miniature Cheddar-type cheeses. Int. Dairy J. 9:473-479.

Quiberoni, A., D. M. Guglielmotti, and J. A. Reinheimer. 2004. New and classical spoilage bacteria causing a widespread blowing in Argentinean soft and semi hard cheeses. Rev. Argent. Lactol. 23:19-31.

Richardson, B. C., and K. N. Pearce. 1981. The determination of plasmin in dairy products. N.Z. J. Dairy Sci. Technol. 16:209220.

Shakeel-Ur-Rehman, , E. P. Feeney, P. L. H. McSweeney, and P. F. Fox. 1998b. Inhibition of residual coagulant in cheese using pepstatin. Int. Dairy J. 8:987-992.

Shakeel-Ur-Rehman, , J. M. Banks, P. L. H. McSweeney, and P. F. Fox. 2000. Effect of ripening temperature on the growth and significance of non-starter lactic acid bacteria in Cheddar cheese made from raw or pasteurized milk. Int. Dairy J. 10:45-53.

Shakeel-Ur-Rehman, , P. L. H. McSweeney, and P. F. Fox. 1998a Protocol for the manufacture of miniature cheeses. Lait 78:607620.

Somers, E. B., M. E. Johnson, and A. C. L. Wong. 2001. Biofilm formation and contamination of cheese by non-starter lactic acid bacteria in the dairy environment. J. Dairy Sci. 84:1926-1936.

Somers, J. M., T. P. Guinee, and A. L. Kelly. 2002. The effect of plasmin activity and cold storage of cheese milk on the composition, ripening and functionality of mozzarella-type cheese. Int. J. Dairy Technol. 55:5-11.

Swearingen, P. A., D. J. O'Sullivan, and J. J. Warthesen. 2001. Isolation, characterization, and influence of native, non-starter lactic acid bacteria on Cheddar cheese quality. J. Dairy Sci. 84:50-59.

Thomas, T. D. 1987. Cannibalism among bacteria found in cheese. N.Z. J. Dairy Sci. Technol. 22:215-219.

Turner, K. W., R. C. Lawrence, and J. Lelievre. 1986. A microbiological specification for milk for aseptic cheesemaking. N.Z. J. Dairy Sci. Technol. 21:249-254.

Upadhyay, V. K., M. J. Sousa, P. Ravn, H. Israelsen, A. L. Kelly, and P. L. H. McSweeney. 2004. Use of exogenous streptokinase to accelerate proteolysis in Cheddar cheese during ripening. Lait 84:527-538

Wilkinson, M. G., T. P. Guinee, D. M. O'Callaghan, and P. F. Fox. 1994. Autolysis and proteolysis in different strains of starter bacteria during Cheddar cheese ripening. J. Dairy Res. 61:249 262.

Williams, A. G., S. E. Withers, and J. M. Banks. 2000. Energy sources of non-starter lactic acid bacteria isolated from Cheddar cheese. Int. Dairy J. 10:17-23. 